PRZEGLĄD RUSYCYSTYCZNY 2019, $\mathrm{nr}$ 4(168)

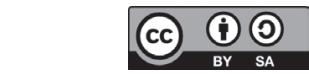

DOI 10.31261/pr.7574

GENNADIJ ZELDOWICZ

Uniwersytet Warszawski

iD ORCID 0000-0003-4437-2802

\title{
ИНФОРМАТИВНОСТЬ ТРОПОВ И КОМПОЗИЦИЯ ЛИРИЧЕСКОГО ТЕКСТА
}

\section{1. ГИПОТЕЗА}

Известно, что в прототипическом случае лирический текст распадается на эмпирическую часть, где представлен какой-то переживаемый автором (или, точнее, лирическим героем - но здесь эта тонкость не слишком существенна) опыт, и часть, так сказать, итоговую, в которой автор приходит к тому или иному обобщению, открытию важной истины и/или в которой существенным образом изменяются его взаимоотношения с миром и/или с самим собой ${ }^{1}$.

Очевидно, будучи предопределено самой природой жанра, именно это противопоставление является основным для лирического текста композиционным разломом, причем посвященные авторскому опыту, эмпирические фрагменты и фрагменты, где совершается названное открытие (в дальнейшем именуем их фокусом), далеко не равноправны: первые содержательно подчинены вторым и уместны лишь в той степени, в какой эти вторые подготавливают, служат им своеобразной когнитивной опорой. Иными словами, эмпирические фрагменты формируют неглавный, или, если воспользоваться термином из нарратологии, «фоновый» план лирического дискурса, а главным планом являются фрагменты фокусные.

1 См. особенно: Т.И. Сильман, Заметки о лирике, Советский писатель, Ленинград 1977. 
Как показывают проводимые нами исследования, оппозиция между эмпирическими частями текста и его фокусом получает вполне конкретные и достаточно последовательные лингвистические манифестации ${ }^{2}$. Например, частыми отличительными особенностями фокуса являются богатство его дискурсивных связей, его референциальная оторванность от иных, эмпирических фрагментов, подчеркнутое особыми средствами типологическое многообразие содержащихся в нем смыслов (речь идет прежде всего о таких типах, как ассерция, пресуппозиция, разного рода импликатуры) и т.д.

Глядя на это явление шире, можно предположить, что если не все, то весьма многие используемые при маркировании фокуса стратегии имеют общий знаменатель: коль скоро фокус обладает большей дискурсивной важностью, должна быть в общем случае более высокой и его информативность. ${ }^{3}$ Разумеется, измерить и сопоставить информативность двух фрагментов текста в целом обычно либо очень трудно, либо невозможно, однако может быть так, что один из фрагментов отчетливо более содержателен в каком-то отдельном и при этом когнитивно хорошо доступном, легко «вычленимом» аспекте своей смысловой структуры (или в нескольких таких аспектах). Скажем, определенно немалой самостоятельностью обладает для нас такой параметр, как типологическое многообразие передаваемой нашими высказываниями информации, а в лирических текстах, повторим, это многообразие нередко еще и дополни-

${ }^{2}$ Г.М. Зельдович, О дискурсивной перспективе в лирической поэзии, «Слова. Слова. Слова» 2015, № 2, с. 456-499; Г.М. Зельдович, Об одном способе маркировать дискурсивную перспективу в лирической поэзии. Композициия и референциальные связи, или В чем неправы П. Хоппер и С. Томпсон, „Linguistica Copernicana” 2015, № 12, с. 245-270; Г.М. Зельдович, «Золотое сечение» и композиция лирического текста, "Wiener Slawistischer Almanach» 2016, № 78, с. 95-148; Г.М. Зельдович, Композиция лирического стихотворения и «теснота» стихового ряда: Типологическое богатство информации как маркер первого дискурсивного плана в лирическом тексте // Людмила Савченко. Душа воспламененная, Харьковский университет, Харьков 2017, с. 273-333 (в печати); G. Zeldowicz, Extraverted consciousness, introverted consciousness, and composition of lyrical discourse, «Linguistica Copernicana» 2016, № 13, c. 301-318.

3 В первом приближении эту информативность можно отождествить с тыняновской «теснотой» стихового ряда, но все-таки это не совсем одно и то же; см.: Г.М. Зельдович, Композиция лирического стихотворения и «теснота» стихового ряда... 
тельно подчеркивается специальными средствами. Поэтому тот факт, что информация, заключенная в фокусе лирического текста, тяготеет к большему типологическому богатству, нежели информация, содержащаяся в эмпирических фрагментах, свидетельствует не просто о стремлении лирического текста каким-то образом отграничить фокус, но также и о том, что «отграничивающим» признаком способна быть более высокая информативность ${ }^{4}$.

Гипотеза, которую мы хотим обосновать в этой работе, такова. Если более высокая информативность, так сказать, «стесненность» смыслового ряда, вообе способна маркировать именно итоговые, фокусные фрагменты стихотворений, то это полностью относится и к разного рода тропам, которые, разумеется, могут быть и более, и менее богатыми по содержанию. Иными словами, мы предполагаем, что более богатый по содержанию троп имеет лучшие шансы оказаться в фокусе и быть его характерной приметой. Дополнительно можно также предположить, что если тропов в последнем несколько, то именно с самым богатым по содержанию тропом должна быть связана наиболее важная его часть.

Безусловно, оценить, насколько информативна та или иная метафора, метонимия, гипербола, литота и т.д., весьма непросто. Согласно теории релевантности, с которой мы склонны в данном вопросе солидаризироваться, к непрямому, фигуральному способу выражения мы прибегаем в первую очередь ради того, чтобы создать некие импликатуры, причем в основном они являются слабыми, такими, за которые автор не несет полную ответственность, зато число их при этом практически не ограничено ${ }^{5}$. Особенно наглядно это свойство проявляет себя у метафор. Скажем, выражение кошачий шаг бедъ способно намекать и на то, что беда подкрадывается незаметно, и на то, что она в том или ином смысле вовсе не тяжела, либо что ее приближение даже доставляет кому-то радость, либо что беду на кого-то навлекла женщина с кошачьей походкой, либо что беда пришла лишь одна - подобно тому, как поодиночке часто ходят кошки,

4 См. подробно снова: Г.М. Зельдович, Композиция лирического стихотворения и «теснота» стихового ряда...

5 См. прежде всего: D. Sperber, D. Wilson, Relevance: Communication and Cognition, Blackwell, Oxford 1995; R. Carston, Thoughts and Utterances. The Pragmatics of Explicit Communication, Blackwell, Oxford 2002. 
и т.Д., и т.д., - и отнюдь не исключен и вариант, когда в той или иной степени актуальны все эти смыслы сразу.

Разумеется, такая же способность к порождению принципиально неограниченного числа слабых импликатур свойственна и весьма многим иным тропам, например гиперболе, литоте, оксюморону и проч. Поэтому, сопоставляя информативность тропов в некотором ряду, на количество соответствующих импликатур ориентироваться нельзя.

И тем не менее, существуют примеры, где подобное сопоставление возможно, только опираться оно должно на иной, уже не количественный, а качественный критерий.

$* * *$

Троп по самой своей природе предполагает, во-первых, наличие определенного предмета или определенной понятийной области, о которых мы хотим сообщить новую информацию (назовем их «характеризуемое»), во-вторых, наличие иного предмета или понятийной области, обращение к которым служит этой цели (в дальнейшем - «характеризующее»). ${ }^{6}$ Например, в только что приведенной метафоре характеризуемым была беда, характеризующим - ее кошачий шаг

В результате взаимодействия между характеризуемым и характеризующим создается некая область их сходств, их «пересечений», область «смешения», или, иначе, бленд (англ. blend) ${ }^{8}$.

6 В западной традиции популярны термины «мишень» (англ. target) и «источник» (source), но для наших целей принятые прозрачные наименования кажутся более удобными.

7 Мы отдаем себе отчет, что четко выявить в метафоре характеризуемое бывает исключительно трудно, а иногда и практически немыслимо (вспомним мандельштамовскую формулировку из Разговора о Данте: «[...] прямому созерцанию, после того как дело метафоры сделано, в сущности, уже нечем поживиться»). Тем не менее, даже при анализе поэтического текста на характеризуемое, пускай и с некоторой долей условности, как правило всетаки можно указать, и именно такими примерами мы займемся ниже.

8 См., в частности: G. Fauconnier, M. Turner, Conceptual integration networks, «Cognitive Science»1988, № 2(22), c. 133-187. На самом деле структура бленда, по Фоконнье и Тернеру, далеко не однородная, иерархическая, но здесь этим можно пренебречь. В настоящем контексте допустимо проигнорировать и то в принципе чрезвычайно важное обстоятельство, что у бленда нередко возникают свойства, которыми не обладало ни характеризуемое, ни 
Характер бленда в разных случаях может быть разным. В зависимости от источника содержащейся в них информации, можно выделить по крайней мере три типа блендов.

Во-первых, бленд могут создавать просто совпадающие либо хорошо сопоставимые свойства характеризуемого и характеризующего. Иначе говоря, соответствующий троп просто выявляem те черты характеризуемого, которые и так имелись в нашем представлении о нем, но не были в достаточной степени актуализированы, а бленд является лишь проекцией общих либо сходных свойств, присущих характеризуемому и характеризующему. Так, по-видимому, дело обстоит в метафоре глаз объектива: о характеризуемом, объективе, наперед известно, что его главная функция - создать зрительный образ предмета, и такова же главная функция глаза. ${ }^{9}$

характеризующее, то есть что бленд по сути дела способен выступать как генератор совершенно новых смыслов.

Стоит добавить, что принятая здесь терминология достаточно легко переводима в термины иных подходов к метафоре, например очень влиятельного подхода, предложенного в статье: S. Gluksberg, В. Keysar, Understanding metaphorical comparisons: Beyond similarity, «Psychological Review» 1990, вып. 97, с. 3-18. По мнению авторов, при образовании метафоры возникает некая «одноразовая», «окказиональная» категория (ad hoc category), членами которой становятся, в частности, и характеризуемое, и характеризующее. Очевидно, что это понятие достаточно хорошо соответствует понятию бленда у Фоконнье и Тернера. Другая, но тоже совместимая с нашими рассуждениями интерпретация метафоры представлена в работах по теории релевантности, см., например: D. Wilson, R. Carston, Metaphor, relevance, and the 'emergent property' issue, "Mind and Language" 2006, nr 3 (21), c. 404-433.

9 Разумеется, названная общность свойств может быть неодинаково очевидной. Что касается характеризуемого, то его релевантные особенности иногда вполне наглядны, а иногда, чтобы их открыть, требуется исключительная проницательность. Если же посмотреть на вещи с точки зрения характеризующего, то существенно, что практически со всяким словом у нас связан ряд представлений, которые нельзя отнести к его семантике. Скажем, слово яблоко вызывает представление, что оно съедобно (хотя смысл этот отменим и не «семантичен»: можно говорить и о несъедобном яблоке), слово медведь - представление о мехе (хотя и лысого медведя вообразить можно), и т.д. Подобные дополнительные представления иногда ассоциируются со словом регулярно, даже там, где отсутствует какая-либо поддержка со стороны контекста (так дело обстоит в только что приведенных примерах), а иногда последней требуют, ср. представление 'может использоваться как опора', которое напрямую не индуцируется словом ящик, но в контексте вроде Передо мной ящик, фужеры, бутылка шампанского. Что же мне использовать в качестве опоры, чтобы украсить игрушками елку? эта особенность нашего понятия о ящике становится хорошо ощутимой; см. подробно 
Во-вторых, присутствие характеризующего может добавлять к нашему первоначальному представлению о характеризуемом нечто существенное, нечто такое, чего мы о нем не могли бы угадать наперед. Например, дни, которые мы проживаем, вообщето могут быть и однообразными, и радостными; поэтому в цветаевской метафоре дней сползающие слизни характеризующее сползающие слизни не просто выявляет сходство двух представлений, но заставляет нас мыслить те дни, которые тут характеризуются, куда более определенно, нежели это было бы в отсутствие данного тропа.

B-третьих, характеризующее может не просто добавлять новое знание о характеризуемом к знанию, уже имеющемуся, но требовать пересмотра наших первоначальных представлений о характеризуемом. Например, оксюморон женатый холостяк чаще всего относится к реально женатому человеку и, таким образом, характеризуемым тут является представление 'мужчина, имеющий жену'. В обычном случае, зная, что кто-то женат, мы предполагаем, что его отношения с женой строятся неким прототипическим образом: он живет с ней под одной крышей, у него нет других женщин и т.д. Однако в присутствии характеризующего холостяк это характеризуемое с неизбежностью и весьма

многочисленные работы Лоренса Барсалоу, например, L.W. Barsalou, Context-independent and context-dependent information in concepts, "Memory and Cognition» 1982, № 11, c. 211-227. Поэтому наглядность, когнитивная доступность соответствующего смысла в характеризующем тоже способна варьировать в достаточно широких пределах. Некоторые авторы образцовой разновидностью метафор считают те, где между характеризующим и характеризуемым не просто обнаруживается сходство, но ответственное за него представление явлено в характеризующем напрямую, безотносительно к контексту (то есть либо принадлежит семантике, либо, не будучи семантическим, все равно оказывается очень регулярным в только что объясненном смысле) - в то время как с характеризуемым оно также связано, однако уже на правах лишь некой изначальной, не очевидной в отсутствие характеризующего потенции; см., например, A. Ortony, Beyond literal similarity, "Psychological Review" 1979, вып. 86, с. 161-180. Скажем, в метафоре Снотворная проповедь у характеризующего снотворная смысл “вызывающая сон' - первоплановый и основной, а для характеризуемой проповедu он, вообще говоря, лишь потенциален и актуализируется здесь главным образом благодаря соседству со снотворная. Очевидно, такие метафоры попадают в названную нами первую категорию тропов, которую и ввиду этого обстоятельства, и с чисто интуитивной точки зрения скорее всего надо считать наиболее прототипической. Впрочем, вопрос слишком сложен, чтобы здесь в него углубляться. 
серьезным образом переосмысляется - то ли вообще в свою противоположность, 'мужчина, не имеющий жены', то ли (что более вероятно) в 'мужчина, имеющий жену, но состоящий с ней в непрототипических супружеских отношениях (живущий отдельно от нее, пользующийся свободой в романтических связях и проч.)'. Так же устроен и метафорический оборот шах истине в знаменитом афоризме Хосе Ортеги-и-Гассета: Идея - это шах истине. Согласно общепринятым представлениям, для истины первостепенно важным является свойство объективности, то, что она не подчиняется человеку (ср. в том же «Восстании масс» замечание, что «истина не в нашей власти»), здесь же она уподоблена шахматному королю и подразумевается возможность объявить ей мат, то есть в известном смысле подчинить ее, взять над ней верх.

Понятно, что прототипически троп третьего типа будет более информативным, чем троп второго, а троп второго типа - более информативным, нежели троп первого. Безусловно, в каждом конкретном случае решить вопрос, какой из тропов информативнее, бывает непросто, ибо в дело способны вмешиваться привходящие обстоятельства: скажем, метафора, только лишь выявляющая сходства между характеризуемым и характеризующим, может оказаться необычайно нова и, значит, информативна просто потому, что сходство это по каким-то причинам нелегко заметить, пускай она его сама и не создает. И тем не менее, на уровне прототипов сказанное остается верным.

С другой стороны, известно, что выразительные средства в поэзии сплошь и рядом опираются как раз на наше представление о прототипе соответствующей категории, а не о какихлибо частных особых случаях.

Скажем, и в русской, и в зарубежной поэзии найдется множество примеров, когда мужской род неодушевленного (!) существительного ассоциирован с чем-то мужественным, сильным, определенным, а женский с женственностью, слабостью, нерешительностью и т.д. Между тем, как известно, существительных, которые называют людей или вообще живые существа, в языке относительно немного, поэтому, рассуждая формально, в большинстве частных случаев названная ассоциация безосновательна - и, тем не менее, она возникает, ибо опирается на идеализированный прототип «мужской род = мужской пол; 
женский род = женский пол» (в свою очередь, прототип этот обязан своим возникновением привилегированному месту человека в нашей картине мира). Аналогичным образом, с глаголом несовершенного вида в поэтической речи (хотя, впрочем, и не только в ней) ассоциируется представление о длительности, протяженности действия - при том, что на самом деле имеется колоссальное количество НСВ с моментальным значением, то есть НCB, обозначающих скачкообразный, лишенный длительности переход от одного состояния мира к другому (ср. хотя бы падать, приходить, находить, проливать (что-то ненароком), терять (ключи, авторучку и т.п.), брать, давать, говорить, что..., предупреждать, прощать и мн. др. $)^{10}$, а вдобавок к этому даже и способные обозначать действие в его протяженности глаголы тоже часто употребляются так, будто бы протяженности этой нет, - в так называемом общефактическом смысле (например, «Дон Кихота» переводил Н. Любимов, где важен сам факт, что перевод состоялся, и важно имя переводчика, но уже нерелевантно, сколько же времени он проработал над Дон Кихотом) ${ }^{11}$.

Таким образом, в поэзии представление о прототипе данной категории сохраняется вполне ясным, когнитивно высокодоступным даже и в неблагоприятных для этого обстоятельствах, даже и тогда, когда ее прототипическая реализация отнюдь не самая частотная.

Отсюда следует, что при определенном взгляде на вещи сама уже принадлежность соответствующих тропов к той или иной из перечисленных выше трех разновидностей способна эти тропы иерархизировать в плане их информативности и, значит, та или иная последовательность тропов в принципе способна маркировать композицию лирического стихотворения.

${ }^{10}$ См. подробнее: Ю.Д. Апресян, Глаголы моментального действия и перформативы в русском языке // Русистика сегодня. Язык: система и ее функционирование, Наука, Москва 1988, с. 219-237.

${ }^{11}$ См. об общефактическом НСВ, например, Е.В. Падучева, Результативные значения несовершенного вида в русском языке: общефактическое и акциональное значение, «Вопросы языкознания» 1993, № 1, с. 64-74, или ряд работ в: Е.В. Падучева, Семантические исследования. Семантика времени и вида в русском языке. Семантика нарратива, Языки русской культуры, Москва 1996; несколько иная интерпретация подобных употреблений несовершенного вида предложена в: Г.М. Зельдович, Прагматика грамматики, Языки славянских культур, Москва 2012. 
Ниже мы представим несколько разборов, которые покажут, что эта теоретическая возможность отнюдь не остается неиспользованной в реальных произведениях лирического жанра.

Добавим еще, что, помимо названных трех «чистых» случаев, существуют и гибридные типы тропов. Например, одна часть соответствующего бленда может быть «спроецирована» в него одновременно и из характеризующего, и из характеризуемого, то есть быть относительно менее информативной, а другая часть создаваться самим характеризующим, возникать как результат смыслового влияния характеризующего на характеризуемое, что, разумеется, означает и бо́льшую информативность. Мы не в состоянии тут построить детальную типологию тропов с учетом этих тонкостей, однако для наших рассуждений достаточно того, что хоть в какой-то мере изменяющий наше представление о характеризуемом троп прототипически более информативен, чем троп, который это представление никаким ощутимым образом не модифицирует.

\section{2. ПРИМЕР 1}

Обратимся к стихотворению Марины Цветаевой:

1.

Дней сползающие слизни,

...Строк поденная швея...

Что до собственной мне жизни?

Не моя, раз не твоя.

2.

И до бед мне мало дела

Собственных... - Еда? Спанье?

Что до смертного мне тела?

Не мое, раз не твое.

Как мы уже выше упоминали, в первой строке, где дни предстают как сползающие слизни, этим наше представление о днях (поэтессы) несомненно модифицируется, ибо вообще-то дни определенного человека могут быть и веселыми, и нудными, и радостными, и неприятными, но интересующая нас метафора часть этих возможностей со всей определенностью исключает. Аналогично дело обстоит и во второй строке. Вообще-то каждая поэтическая строка в нормальном случае обладает неповтори- 
мостью и как творца неповторимых строк мы воспринимаем поэта; однако, с другой стороны, строки в стихах обычно достаточно многочисленны, так что с определенной, хотя и далекой от привычного точки зрения, тут можно увидеть, наоборот, низкую индивидуализированность, так сказать, «оптовость» - и именно на нее указывает метафора поденная швея, меняя, таким образом, наше изначальное представление о характеризуемых тут сущностях: о создаваемых поэтом строках и о самом поэте.

Таким образом, тут обе метафоры устроены «аддитивно», они дополняют, уточняют наше изначальное представление о характеризуемом.

Однако два следующих тропа-оксюморона, 'моя жизнь не моя', 'мое тело не мое', идут еще дальше. Если в предыдущих случаях представление о характеризуемом (днях, строках) обогащалось лишь во вполне определенных аспектах (однообразие дней; однообразие строк), то здесь характеризуемое, 'моя жизнь' и 'мое тело', и характеризующее, соответственно, 'не моя жизнь' и 'не мое тело', полностью отождествляются, «сливаются», так что, по сути, пересматриваются все наши первоначальные знания о характеризуемом: все то или по крайней мере очень многое из того, что можно было бы сказать о «не моей жизни» и «не моем теле», верно также и применительно к жизни «моей» и телу «моему» (автор своей жизнью и своим телом не распоряжается; автор свою жизнь и свое тело вообще не воспринимает как нечто ему принадлежащее; автор не чувствует ответственности ни за одно, ни за другое; автору его жизнь и его тело не доставляют радости; автор мало что знает о своей жизни и о своем теле, и т.д.).

Между тем, именно строка 4, Не моя, раз не твоя, и строка 8, Не мое, раз не твое, и прочитываются в этом стихотворении как его фокус, его главный содержательный итог (первая как итог в определенном смысле еще «предварительный», а вторая - «окончательный»). Из изложенного видно, что их фокусный статус маркирован более высокой информативностью представленных в них тропов.

\section{3. ПРИМЕР 2}

Подробнее проиллюстрировать наш тезис о вероятной связи между дискурсивным статусом соответствующего фрагмента 
и смысловой насыщенностью тропеических средств поможет более пространное и более богатое последними «Воспоминание» Болеслава Лесьмяна (оригинальное название - „Wspomnienie”; перевод наш - GZ; предметом анализа будет именно русская версия - хотя в главных интересующих нас особенностях она мало отличается от подлинника):

1.

Та тропа, те ребячьи ботинки -

Где они? Где их встретишь еще ты?

Расплылись, как слезинки, И скатились в пустоты!

2.

Просыпался от сырости свежей -

И ко мне выплывало из сони

Солнце дальнебережий,

Солнце добрых бездоний...

3.

Кто заклятвенно смотрит отсюда,

Как блистанье безмолвьем плотнится,

Тот однажды увидит и солнце-верблюда,

И разбойника с солнцем в зенице...

4.

Я на завтрачной скатерти видел картину:

Я бродяга-разбойник... Скачу я по свету...

А отец будто знал, что его я обмину, -

И листал безмятежно газету...

5 .

Было красно, и желто, и сине

В троерадужном блеске кувшина.

То ль оса заблудилась в гардине -

То ли нитью бренчала гардина...

6.

И зеркалился пол, подавшись к занавеске,

Отпечатками листьев со светлым исподом -

Но в таком примутненном, разбавленном блеске,

Словно зелень плеснули туда мимоходом.

7.

Все лысей и морщинней,

Кресло вжилось во время...

Сахар искрою синей

Прорезался из теми...

8.

Вытрясали часы из пружинных извилин

Бесконечную ноту.

И был каждый бессмертен, был каждый всесилен, Дни тянулись без счету... 
9.

А потом налетело - потом налетело...

Я робел от удара к удару...

И споткнулась душа о безмежное тело -

И умирали на пару...

Рассмотрим присутствующие в этом стихотворении тропы.

В первой строфе появляется метафорическое сравнение распльлисъ, как слезинки. Известно, что слезинка или, вообще, капля жидкости в прототипическом случае не существует долго и, упав, теряет свою форму. Вместе с тем, тропа и ботинки, которые здесь характеризуются, суть образы прошлого, а такой образ обычно со временем теряет для нас свою отчетливость и тоже становится слабо «опознаваемым». (Добавим еще, что если даже у каких-то авторов это обстоит иначе, для Лесьмяна подобное граничащее с предательством забвение прошлого, то, что, выражаясь его же словами, «умирающий вновь умирает в могиле», было сквозным мотивом всего поэтического творчества). Отсюда видно, что в возникающий бленд, в первом приближении - 'нечто перестает быть хорошо опознаваемым, теряет свою форму', проецируются не только важные свойства характеризующего, но и в характеризуемом их тоже легко предполагать наперед.

Далее, коль скоро в первой половине этой строфы уже утверждено сходство двух образов со слезинками, то вовсе не становится неожиданностью их способность скатываться; что же касается их скатывания именно в пустоты, то есть исчезновения, то и эта деструкция для любых пребывающих в памяти образов (а особенно - в творчестве Б. Лесьмяна) угадывается почти так же уверенно, как постепенная потеря ими своей формы. Поэтому и следующая метафора, скатились в пустоты, не столько обогащает наше знание о характеризуемом, сколько те или иные стороны этого знания попросту отчетливее выявляет.

Во второй строфе метафора «солнце выплывает» достаточно конвенциональна, главное же, с характеризуемым-солнцем в нашей картине мира прочно ассоциируется представление о движении, в том числе о движении откуда-то, где солнце не видно, к полю нашего зрения (проще говоря - о восходе), а вдобавок еще и представление о плавности этого движения - так что и здесь важная часть смысла, заключенного в характеризующем выплывает, из самого характеризуемого с некоторой отнюдь не ничтожной вероятностью может быть угадана. Иными 
словами, и этот троп изменяет наше видение характеризуемого в весьма ограниченных пределах.

Позднее появляются многочисленные тропы, которые это видение меняют уже более серьезно.

Сначала изменения происходят «аддитивным» путем: к изначальному представлению добавляется нечто новое, но не меняется в корне само это представление. Оборот смотреть заклятвенно относит нас к необычному, наперед не предугадываемому способу смотреть ( 'смотреть, как бы заклиная что-то взглядом, вызывая в чем-то волшебные изменения'), однако само характеризуемое смотреть сохраняет все свое исходное значение. Что бы ни означало в тонкостях блистанъе безмолвъем плотнится, характеризуемое блистанъе относит нас к той же сущности, к какой бы относило и в обычном, нетропеическом контексте. В выражении солнце-верблюд подразумевается верблюд, озаренный солнцем (в оригинале - букв. 'солнечный верблюд', stoneczny wielbład), то есть, вновь-таки, характеризуемое сохраняет свои важнейшие изначальные свойства, лишь обогащая их новыми, заимствованными у характеризующего; аналогично для разбойника с солнцем в зенице. Подобным же образом, чтобы нитью бренчала гардина, нить должна своим дрожанием и производимым звуком уподобиться струне, однако это не мешает ей оставаться все той же нитью. Наконец, и чтобы (зеркальному, налощенному) полу податься $\kappa$ занавеске, то есть, скорее всего, ее просто отразить, никаких принципиальных метаморфоз с ним произойти не должно.

Дальше предполагаемые тропами деформации в нашем представлении о характеризуемом становятся серьезнее. Зелень, которую плеснули куда-то мимоходом, во-первых, обретает особое, наперед не предсказуемое качество примутненности; это, конечно, пока еще аддитивная трансформация такого же типа, с каким мы встретились выше. Однако, во-вторых, будучи вообще-то цветом, зелень как бы становится вдобавок и жидкостью, то есть уже меняет свою категориальную природу. Во фразе кресло вжилось во время у характеризуемого кресло и характеризующего время есть некая важная общая и наперед угадываемая черта, а именно, «старость»: время и вообще принято мыслить как нечто древнее и протяженное (ср. хотя бы у Фернандо Пессоа: «Я старше времени во много раз»), а о кресле в предыдущей строке сказано Все лысей и морщинней... - так 
что и для кресла его почтенный век заранее тут известен. Но, с другой стороны, помимо такого аддитивного эффекта, эта метафора создает и еще один: кресло уподобляется живому существу, почти наверняка человеку, ибо лишь живые существа, и человек прежде всего, способны во что-то вживаться; в результате сама категориальная природа кресла резко меняется. ${ }^{12}$ В строках Сахар искрою синей Прорезался из теми..., во-первых, к представлению о сахаре аддитивно присоединяется смысл 'сахар был источником синих искр', а во-вторых, сахар еще - меняющим саму его концептуализацию образом - предстает как нечто острое, способное прорезаться. Далее, в Вытрясали часы из пружинных извилин Бесконечную ноту между нотой и чемто иным, что может вытрясаться из пружины (пыль? мусор?), есть очевидная бесхитростная общность: и то, и другое так или иначе «продуцируется» пружиной, становится явным благодаря ее движению, так что приведенная метафора безусловно выявляет наперед угадываемые сходства между характеризуемым и характеризующим. Однако, помимо этого «аддитивного» эффекта, есть и другой, информативно более весомый, ибо такая исконно событийная, непредметная по природе сущность, как нота, уподоблена предмету либо веществу.

Пропустив оборот удар за ударом, ибо метафора удары судъбы сугубо конвенционализированная и едва ли должна тут входить в расчет, посмотрим на заключительные и несомненно фокусные строки, И споткнулась душа о безмежное тело И умирали на пару... Очевидно, какую бы общность мы ни усмотрели тут между взаимоотношениями души и тела и ситуацией «кто-то споткнулся обо что-то (об кого-то)», она непременно требует мысленно «овеществить» душу, перевести ее в несвойственную ей онтологическую категорию, так что, в отличие от предыдущих случаев, никакого ясного смысла, который мог бы просто присоединиться к первоначальному концепту души, эта метафора не создает.

${ }^{12}$ Источник аналогичного эффекта можно усмотреть и в словах Все лысей и морщинней..., если выступающие тут прилагательные считать метафорическими, переносящими на кресло смыслы из человеческого мира. С другой стороны, слова лысый и морщинистый (и, по аналогии, употребленное тут более редкое морщинный) так широко прилагаются к неодушевленным предметам (ср. лысая шуба, лысый воротник, лысое колесо; морщинистая кожа, морщинистое пальто, морщинистая краска на стене и проч.), что наличие тут сколько-нибудь ощутимой метафоры все же сомнительно. 
Таким образом, на своем тропеическом уровне это стихотворение весьма последовательно развертывается от речевых фигур, которые только лишь выявляют наперед существующее или скорее всего наперед существующее сходство между характеризуемым и характеризующим, сперва к фигурам, которые к изначальному представлению о характеризуемом лишь добавляют новые смыслы, затем к фигурам, которые и, в одном плане, просто добавляют новые смыслы к первоначальному представлению, и, в плане другом, одновременно требуют также рекатегоризации характеризуемого, пересмотра наших о нем изначальных представлений, - и, наконец, в заключительной части появляется метафора, которая носит уже всецело рекатегоризационный характер.

Понятно, что на каждом этапе этой эволюции мы сталкиваемся с прототипически все более и более информативными тропами, поэтому едва ли следует удивляться, если именно чисто рекатегоризационная, а не какая-либо иная метафора маркирует собой итоговые строки этого стихотворения.

\section{4. ПРИМЕР 3}

По всей видимости, тенденция к регулярному и ориентированному на структурирование лирического дискурса распределению тропов по возрастающей информативности исключительно характерна для Осипа Мандельштама. Вот один из прекрасных примеров:

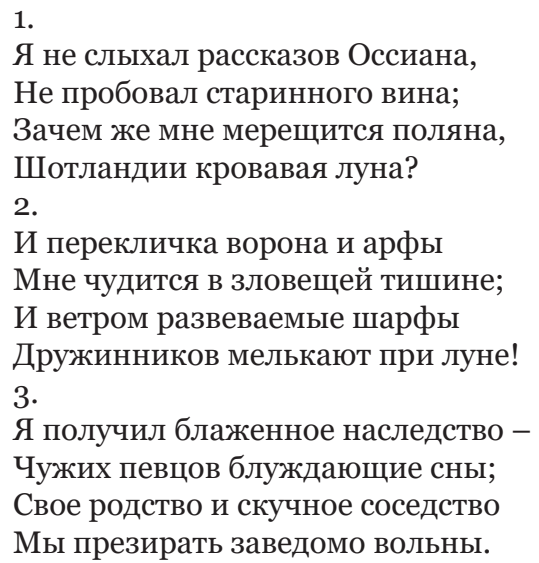


4.

И не одно сокровище, быть может,

Минуя внуков, к правнукам уйдет;

И снова скальд чужую песню сложит

И, как свою, ее произнесет.

В строфах 1-2 тропов нет.

Когда в строфе 3 появляются метафоры 'получение наследства', 'родство' и 'соседство', их содержание нельзя считать совершенно новым и неожиданным. Действительно, уже из первых двух строф ясно, что поэт что-то получил от прошлых эпох. Частным, но весьма прототипическим способом получить что-то из прошлого является наследование, наследование же связано обычно с родством. Поскольку же наследуются тут не материальные ценности, но некие ментальные конструкты (ближайшим образом, представление о поляне, кровавой луне, перекличке ворона и арфы и т.д.) и поскольку в прототипическом случае два человека, наблюдающие одну и ту же картину, смотрят на нее одновременно или почти одновременно и находятся близко друг к другу в пространстве, постольку и переход к идее соседства в строках 11-12 вполне логичен и в принципе вполне предсказуем из строк 1-10. Такого же рода и метафора 'сокровище' в строфе 4- ибо сокровища в наиболее прототипическом случае суть ценности, которые должны быть кем-то унаследованы.

Поэтому хотя метафоры тут и заставляют по-новому увидеть свое характеризуемое, обогащают представление о нем, в немалой степени их роль состоит в том, чтобы просто актуализировать такие особенности характеризуемого, которые все-таки с достаточно большой вероятностью предсказуемы наперед, помимо самой метафоры.

С другой стороны, никоим образом не допустимо предполагать наперед, что песню (стихи), сочиненную одним человеком, сочинит другой человек, и в этом смысле тропика двух заключительных, а вместе с тем фокусных строк по своей информативности радикально богаче, чем тропы в эмпирических фрагментах стихотворения.

\section{5. ПРИМЕР 4}

Несколько по-иному обсуждаемая закономерность проявляется в стихотворении Мандельштама Айя-София: 
1.

Айя-София - здесь остановиться

Судил Господь народам и царям!

Ведь купол твой, по слову очевидца,

Как на цепи, подвешен к небесам.

2.

И всем векам - пример Юстиниана,

Когда похитить для чужих богов

Позволила Эфесская Диана

Сто семь зеленых мраморных столбов.

3 .

Но что же думал твой строитель щедрый,

Когда, душой и помыслом высок,

Расположил апсиды и экседры,

Им указав на запад и восток?

4.

Прекрасен храм, купающийся в мире,

И сорок окон - света торжество;

На парусах, под куполом, четыре

Архангела прекраснее всего.

5 .

И мудрое сферическое зданье

Народы и века переживет,

И серафимов гулкое рыданье

Не покоробит темных позолот.

В первом появляющемся здесь тропе, метафоре-сравнении Ведь купол твой, по слову очевидца, Как на цепи, подвешен к небесам, характеризующее 'купол подвешен к небесам' отчасти дополняет наше изначальное представление о характеризуемом купол: то, что купол близок к небу и связан с ним ощутимее, чем с землей, отнюдь не предопределяется нашим априорным представлением о куполах. Тем не менее, сама «оторванность» купола от земли, на которую указывает характеризующая часть тропа, в этом априорном представлении несомненно присутствует.

Что касается следующей метафоры, 'строитель указал апсидам и экседрам на запад и восток', то здесь, очевидным образом, в качестве характеризуемого выступает представление, что строитель, создавая апсиды и экседры, определенным образом их расположил, а представление, что он именно указал им на запад и восток, так, будто они обладали собственной волей и способностью ему подчиниться либо не подчиниться, - это уже характеризующее. Разумеется, глядя на те или иные архитектурные элементы, мы обычно не склонны думать о связи между их пространственной ориентацией и чьим-то 
указанием. Поэтому причинно-следственное отношение 'апсиды и экседры ориентированы данным образом потому, что кто-то так велел' скорее создается характеризующей частью метафоры и добавляется здесь к представлению о характеризуемом. С другой стороны, сама обращенность апсид и экседр на запад и восток весьма типична для православного собора, и представление о ней не только прямо выражается в характеризующем, но почти наверняка заведомо ассоциируется и с характеризуемым.

Далее, как бы ни понимать мир в метафоре Прекрасен храм, купающийся в мире (можно как, приблизительно выражаясь, 'вселенная', можно как 'спокойствие'), ясно, что храм в мире так или иначе пребывает, что это характеризуемое и что характеризующим выступает тут представление о купании, представление, благодаря которому наш концепт 'пребывания в мире' нетривиальным образом обогащается. Вместе с тем, купанием в мире, конечно же, имплицируется и пребывание в нем, так что у характеризуемого и характеризующего есть важная общая часть.

Точно так же, в следующей метафоре характеризуются сорок окон, а света торжество выступает в качестве характеризующего, которое несомненно добавляет к представлению об окнах нечто новое (а именно - идею могущества и радости), однако наполняющий их свет, разумеется, всецело «подсказывается» самим уже характеризуемым.

Таким образом, перед нами целый ряд тропов, в каждом из которых наше представление о характеризуемом существенно обогащается благодаря характеризующему, но, во-первых, обогащение тут происходит путем добавления к этому представлению определенной информации, а не его пересмотру, во-вторых, в то же время характеризуемое и характеризующее обладают и достаточно важной заведомой, присущей им изначально, независимой от данного тропа общностью.

Что же касается финальной метафоры, И серафимов гулкое рыданъе Не покоробит темнъх позолот, то она резко разрушает установившуюся инерцию.

Очевидно, в роли характеризуемого тут выступает представление 'позолоты (не) покоробятся', а в роли характеризующего - 'серафимы своим гулким рыданьем (не) каузируют ситуацию «позолоты покоробятся»'. Разумеется, в буквальном смысле рыдание серафимов не может покоробить позолоты, 
и, следовательно, оно как каузатор соответствующей ситуации лишь уподобляется иному, так сказать, «буквальному», каноническому каузатору, так что каузация тут приобретает почти наверняка метафорический характер. Каков же тогда этот «буквальный» каузатор? В таком качестве способно выступить огромное, едва ли даже вообще обозримое число разнообразных обстоятельств: влажность, сухость, холод, жара, землетрясение, произошедший поблизости взрыв, проседание стен, осыпавшаяся штукатурка, проводимые в соборе дополнительные строительные либо отделочные работы, и т.д., и т.д., - причем, судя по всему, ни одна из этих возможностей не имеет в данном контексте весомого преимущества перед иными, то есть каузатор, каков он в рамках характеризуемого, остается в высокой степени неопределенным ${ }^{13}$.

У дела, однако, есть и другая сторона. Коль скоро этот подразумеваемый характеризуемым каузатор получает совершенно конкретное, специфическое отображение в составе характеризующего, то логично думать, что таким же конкретным - пускай даже и не называемым прямо - он должен быть и в самом характеризуемом.

Иначе говоря, присутствие обсуждаемого характеризующего означает, что в характеризуемом на представление о неконкретизированности каузатора наслаивается противоположное представление - о его достаточно высокой определенности. Это, конечно, вовсе не то аддитивное приращение смысла, какое имело место в предшествующих тропах. И для наших представлений о мире в целом, и для данного характеризуемого в частности внутренняя противоречивость является свойством столь необычным, столь «противозаконным», выводящим их из ряда вон, что ее возникновение кореннъмм образом изменяет саму изначальную природу их содержания.

Как видим, в данном отношении влияние характеризующего на характеризуемое тут несоизмеримо значительнее, чем это было в предыдущих случаях, а следовательно, неизмеримо выше и информативность этого тропа, которая делает заключительные строки дискурсивно выделенными.

${ }^{13}$ Связывать рыдание с влажностью представляется тут вопиюще безвкусным. Кроме того, в концепте рыдания на первом плане скорее соответствующий звук, а не слезы. 


\section{6. ПРИМЕР 5}

Очень выразительным примером может быть стихотворение Арсения Тарковского:

1.

Я прощаюсь со всем, чем когда-то я был

И что я презирал, ненавидел, любил.

2.

Начинается новая жизнь для меня,

И прощаюсь я с кожей вчерашнего дня.

3 .

Больше я от себя не желаю вестей

И прощаюсь с собою до мозга костей, 4.

И уже, наконец, над собою стою,

Отделяю постылую душу мою,

5 .

В пустоте оставляю себя самого,

Равнодушно смотрю на себя - на него.

6.

Здравствуй, здравствуй, моя ледяная броня,

Здравствуй, хлеб без меня и вино без меня,

7.

Сновидения ночи и бабочки дня,

Здравствуй, все без меня и вы все без меня!

8.

Я читаю страницы неписаных книг,

Слышу круглого яблока круглый язык,

9.

Слышу белого облака белую речь,

Но ни слова для вас не умею сберечь,

10.

Потому что сосудом скудельным я был

И не знаю, зачем сам себя я разбил.

11.

Больше сферы подвижной в руке не держу

И ни слова без слова я вам не скажу.

12.

А когда-то во мне находили слова

Люди, рыбы и камни, листва и трава.

Интуитивным фокусом тут является заключительное двустишие, а все предшествующие ему по содержанию скорее эмпиричны.

Хотя эмпирическая часть текста содержит множество метафор, во всех в них либо обнаруживается и без того существо- 
вавшее сходство между характеризуемым и характеризующим, либо к исходному представлению о характеризуемом только добавляется некая важная информация - но нигде наше первоначальное представление о характеризуемом не подвергается модификациям. Так, если во втором двустишии нечто уже изжитое автором (изжитые мысли, чувства, стремления и т.д.) дополнительно осмысляется как сбрасывание кожи, в третьем, четвертом и пятом освобождение от этих мыслей, чувств и проч. предстает как прощание с самим собой и отделение от себя своей прежней души, в шестом же чувство защищенности и отстраненности метафоризируется как «ледяная броня»; если в восьмом и девятом какие-то свойства яблока и белого облака концептуализируются как дар слова; если в десятом те или иные черты автора перекликаются со свойствами «скудельного сосуда» - то нигде тут не видно причин, почему какие-то исходно наличные в характеризуемом смыслы должны были бы при этом видоизменяться или «зачеркиваться».

В заключительном двустишии ситуация иная. Характеризуемым в присутствующей тут метафоре, то есть, так сказать, неметафорическим компонентом ее содержания, является представление, согласно которому нужные слова (для людей, рыб, камней и т.д. или же о людях, рыбах, камнях и т.д.) находил сам автор. В то же время характеризующее 'во мне находили слова люди, рыбы, камни...' вполне допустимо и даже предпочтительно понимать в том смысле, что люди, рыбы и т.д. были активными «словоискателями» и «словосозидателями», автор же - скорее пассивным, а не деятельным началом, своего рода «местом», где слова обнаруживались.

Вновь-таки, характеризующее тут заставляет нас пересмотреть наши исходные представления о характеризуемом, и вновь-таки, происходит это в фокусе лирического текста.

\section{7. ПРИМЕР 6}

Несколько иной поворот эта же тема получает в другом стихотворении Арсения Тарковского, «Бессонница»:

1.

Мебель трескается по ночам.

Где-то каплет из водопровода. 
От вседневного груза плечам

В эту пору дается свобода,

2.

В эту пору даются вещам

Бессловесные души людские,

И слепые,

немые,

глухие

Разбредаются по этажам.

3 .

В эту пору часы городские

Шлют секунды

Туда

и сюда,

И плетутся хромые, кривые,

Подымаются в лифте живые,

Неживые

и полуживые,

Ждут в потемках, где каплет вода,

Вынимают из сумок стаканы

И приплясывают, как цыганы,

За дверями стоят, как беда,

Сверла медленно вводят в затворы

И сейчас оборвут провода.

4.

Но скорее они - кредиторы

И пришли навсегда, навсегда,

И счета принесли.

Невозможно

Воду в ступе, не спавши, толочь,

Невозможно заснуть, - так

тревожна

Для покоя нам данная ночь.

Очевидно, когда в строках 3-4 жизненные трудности предстают как груз на плечах, когда далее предметы наделяются душой, а секунды уподобляются людям или иным человекоподобным существам, то происходит несомненная рекатегоризация наших изначальных понятий: трудности, вообще говоря, не физический объект, предметы - объекты неодушевленные, а секунды не живые существа.

В то же время эти элементы характеризуемых смыслов не обладают высокой когнитивной привилегированностью, ибо в обычном случае, без особой поддержки контекста они осознаются нами достаточно слабо: так, если бы нас попросили истолковать концепты жизненных трудностей, предметов и секунд, 
о непринадлежности первых к физическим объектам и о неодушевленности вторых и третьих мы бы едва ли вообще эксплицитно упомянули - разве что нас бы к этому вынудили какие-то особые дополнительные обстоятельства.

Поэтому, хотя переосмысление характеризуемого тут несомненно происходит, оно должно оказаться относительно малозаметным - и уж во всяком случае куда менее заметным, чем переосмысление секунд в более поздних строках Но скорее они - кредиторы И пришли навсегда, навсегда..., где секунды перестают быть мимолетными, перестают (быстро) сменять друг друга - то есть лишаются уже такого своего свойства, которое нормально находится для нас на первом, важнейшем когнитивном плане и которое в обычном случае сразу же приходит на ум, если мы думаем о соответствующем концепте.

Говоря несколько по-иному, интересующее нас различие заключается в том, что в первом случае в понятиях жизненных трудностей, предметов и секунд метафора заставляет нас пересмотреть некие фоновые элементы - пересмотреть саму категориальную принадлежность соответствующих феноменов, а во втором случае - подвергнуть ревизии более специфическую часть их содержания, их, так сказать, смысловой фокус (об этом же часто говорят в терминах «фон» и «фигура», «база» и «профиль» и т.п.). Междутем, хорошо известно, что какраз болееспецифическая, отличающая данное понятие от максимального числа иных сопоставимых понятий его часть тяготеет к когнитивной привилегированности, к тому, чтобы быть особенно заметной ${ }^{14}$.

Как видим, обсуждаемые метафоры расположены в тексте далеко не случайным образом: первой появляется та, в которой изначальный смысл характеризуемого не модифицируется, затем та, в которой он модифицируется, но модификация затрагивает относительно малозаметную его часть, затем метафора, где модифицируемый компонент смысла заметен в очень высокой степени - и это должно по крайней мере в нашем субъективном восприятии делать ее более информативной.

Примечательно, разумеется, что такая наивысшая информативность тропа достигнута в начале четвертой строфы, которая в целом прочитывается как фокус стихотворения.

${ }^{14}$ Cм., например: L. Talmy, Attention phenomena // D. Geeraerts, H. Cuyckens, ред., The Oxford Handbook of Cognitive Linguistics, Oxford University Press, Oxford 2010, c. 264-293. 


\section{8. ПРИМЕР 7}

Как мы помним, выдвинутая в начале гипотеза была, по сути, двучастной. С одной стороны, мы считаем, что наиболее информативный из используемых поэтом тропов скорее должен попасть в фокус лирического текста, - и рассмотренным выше материалом это прекрасно подтверждается. С другой стороны, дополнительно мы предположили, что если тропов в фокусе несколько, то именно с самым богатым по содержанию тропом должна быть скорее всего связана наиболее важная его часть. Чтобы это предположение убедительно подтвердить, требуется проанализировать куда больше текстов, чем это нами сделано до сих пор. Тем не менее, два очень выразительных и согласующихся с ним примера мы хотели бы привести.

Первым будет Ламарк Осипа Мандельштама:

1.

Был старик, застенчивый как мальчик, Неуклюжий, робкий патриарх...

Кто за честь природы фехтовальщик?

Ну, конечно, пламенный Ламарк.

2.

Если все живое лишь помарка

За короткий выморочный день, На подвижной лестнице Ламарка Я займу последнюю ступень.

3 .

К кольчецам спущусь и к усоногим, Прошуршав средь ящериц и змей, По упругим сходням, по излогам Сокращусь, исчезну, как Протей.

4.

Роговую мантию надену,

От горячей крови откажусь,

Обрасту присосками и в пену

Океана завитком вопьюсь.

5 .

Мы прошли разряды насекомых

С наливными рюмочками глаз.

Он сказал: природа вся в разломах,

Зренья нет - ты зришь в последний раз.

6.

Он сказал: довольно полнозвучья,

Ты напрасно Моцарта любил,

Наступает глухота паучья,

Здесь провал сильнее наших сил. 


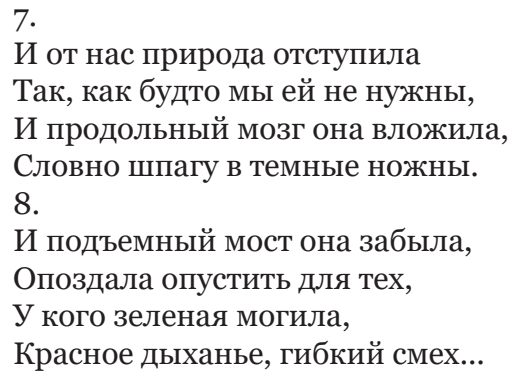

Не будем анализировать тропеический пласт стихотворения целиком, но сосредоточимся на седьмой-восьмой строфах.

Очевидно, что важнейшей, дискурсивно наиболее привилегированной частью этого текста является его финал, скорее всего заключительное ...тех, У кого зеленая могила, Красное дыханъе, гибкий смех... Остальная часть строф 7 и 8 тоже скорее должна быть признана фокусной, однако соответствующие фрагменты все равно исполняют в пределах такого обширного фокуса несомненно подчиненную заключительному фрагменту роль и оттого их дискурсивный ранг несколько ниже.

При этом, хотя и седьмая строфа, и строфа восьмая насквозь тропеичны, все же тропы «главного фокуса» в обсуждаемом плане ощутимо информативнее, чем тропы в строфе 7 и в начале строфы 8.

Выступающие в строфе 7 и в начале строфы 8 метафоры обладают тем хорошо уже знакомым нам свойством, что характеризующее отчасти обогащает, дополняет наше представление о характеризуемом, но в то же время и достаточно важная общая часть у них тоже заведомо присутствует.

В строке И от нас природа отступила характеризуемым является идея о некотором эволюционном, когнитивном, эмоциональном и т.п. расстоянии между человеком и природой, а характеризующим - мысль, что радикально увеличилась между ними физическая дистанция. Идея этого увеличения, неравенства между нынешним и прежним положением вещей изначально отсутствовала в характеризуемом и проецируется тут в него из характеризующего. Однако представление о самой соответствующей дистанции - в буквальном или образном ее понимании - настолько тут «заведомо», загодя знакомо (хотя бы из предыдущих частей все того же «Ламарка», где взаимоотношения между человеком и иными формами жизни концеп- 
туализировались именно в пространственных терминах: можно занять место на соответствующей лестнице, спуститься к другим, более примитивным существам и т.д.), что едва ли может считаться собственным вкладом характеризующего в значение данной метафоры: оно тут скорее является изначально общцим для характеризуемого и характеризующего.

Таким образом, перед нами метафора, где бленд возникает отчасти из заведомо присущих и характеризующему, и характеризуемому смысловых элементов, а отчасти из элементов, которые характеризующее «навязывает» характеризуемому.

Подобная картина и в следующей метафоре-сравнении, И продольный мозг она вложила, Словно шпагу в темные ножны. Характеризуемым тут становятся определенные особенности мозга, характеризующим - представление о шпаге и о наиболее типичном способе ее хранения. Очевидно, шпага относится к продолговатым предметам, однако продолговатость (продольность) с помощью соответствующего прилагательного приписывается тут мозгу еще и независимо, отдельно от интересующей нас метафоры - так что, с точки зрения ее устройства, представление о продолговатости является чем-то заведомо, изначально общим для ее характеризуемого и характеризующего, а не привносится благодаря последнему.

С другой стороны, то, что мозг, подобно шпаге, находится в своей защитной оболочке, и то, что, подобно шпаге, он служил орудием (эволюционной) борьбы, - достаточно далеко от заведомой очевидности и более похоже на смыслы, которые «наводятся» характеризующим и обогащают наш концепт характеризуемого.

Далее, в И подъемный мост она забыла, Опоздала опустить [для людей] по-новому характеризуется та дистанция, тот «разлом» между человеческим и животным миром, которые уже были раньше «темой» метафоры И от нас природа отступила. Идея, что два мира можно было бы друг с другом связать, наперед здесь не очевидна и создается именно характеризующим, образом подъемного моста, представление же о самой взаимооторванности имеется изначально и в характеризующем, и в характеризуемом.

Итак, во всех этих случаях, с одной стороны, между характеризуемым и характеризующим присутствует важное заведомое сходство, с другой же, характеризующее обогащает наши пред- 
ставления о характеризуемом, но делается это аддитивно, через добавление новых смыслов, не заставляющее пересматривать прежде имевшийся у нас ментальный образ характеризуемого.

Иначе устроена следующая метафора (или, если угодно, своего рода «метонимическая метафора»), красное дъханъе. Здесь концепт красное, выступающий в роли характеризующего, не имеет с дыханъем заведомых сходств, а потому здесь требуется, чтобы представление о дыхании подверглось в возникающем бленде значительной рекатегоризации: у дыхания появляется такой вообще-то ему наотрез не свойственный признак, как цвет.

Правда, теоретически между дыханьем и кровью можно найти заведомое, независимо от данной метафоры существующее сходство, ибо дыханье обычно теплое, красный же цвет (конечно, уже в переносном, зато вполне конвенционализированном смысле) принадлежит к теплым цветам, а вдобавок прототипический представитель красного - кровь, тоже обычно теплая, - но этот интерпретационный путь очевидным образом связан с весьма большими и вряд ли оправданными когнитивными затратами.

Наконец, в заключительной метафоре гибкий смех, вопервых, у характеризуемого смех и характеризующего гибкий все так же нет общих «заведомых» черт, во-вторых, для смеха требуется серьезная рекатегоризация (у него появляется такой неожиданный параметр, как способность/неспособность легко изменять свою форму), в-третьих, избежать рекатегоризации здесь нельзя даже тем несколько сомнительным способом, каким это допустимо было бы сделать в предыдущем случае.

Как видим, на тропеическом уровне финальный фрагмент «Ламарка» уверенно движется от речевых фигур, где представление о характеризуемом и представление о характеризующем обладают изначальной общей частью и при этом характеризующее лишь расширяет наш концепт характеризуемого, к речевым фигурам, где изначальной общности нет, а вдобавок присутствие характеризующего заставляет нас пересмотреть наше «базовое» представление о характеризуемом, причем сначала этот пересмотр выглядит как нечто в принципе избежимое, а затем становится «неотвратным».

Иными словами, по своей структуре тропы все яснее и яснее стремятся к высокой информативности, максимум которой совпадает с финалом стихотворения и одновременно с его дискурсивно самым привилегированным фрагментом. 


\section{9. ПРИМЕР 8}

Обратимся еще к одному к стихотворению Осипа Мандельштама:

1.

В таверне воровская шайка

Всю ночь играла в домино.

Пришла с яичницей хозяйка,

Монахи выпили вино.

2.

На башне спорили химеры:

Которая из них урод?

А утром проповедник серый

В палатки призывал народ.

3 .

На рынке возятся собаки,

Менялы щелкает замок.

У вечности ворует всякий,

А вечность - как морской песок:

4.

Он осыпается с телеги -

Не хватит на мешки рогож, -

И, недовольный, о ночлеге

Монах рассказывает ложь!

Тропеические фигуры появляются тут лишь ближе к концу, в третьей и четвертой строфах.

В метафоре У вечности ворует всякий человеческая жизнь как характеризуемое сопоставляется с вечностью как характеризующим: грубо говоря, имеется в виду, что в жизнь отдельного человека вторгаются проблески вечности, что человек ищет для себя нечто такое, что выходило бы за границы его повседневной жизни. С другой стороны, наперед очевидно - а вдобавок и весьма важно для разбираемых стихов, - что не только в вечности, но и в жизни есть множество возможностей, которые человек упускает или которыми готов злоупотребить. Иными словами, соответствующий бленд по крайней мере в значительной его части создают представления, для нас заведомо связанные и с характеризующим-вечностью, и с характеризуемым-жизнью. Даже более того, если тут и есть влияние одного представления на другое, то растрату сил и возможностей естественнее приписать обычной человеческой жизни, ибо в вечности мы склонны видеть неистощимое, «неоскудное» хранили- 
ще потенций. В таком случае тут область характеризующего на самом деле обогащается за счет характеризуемого - ситуация, откровенно редкостная и делающая метафору еще менее содержательной, еще менее способной расширять наши знания о характеризуемом.

Далее, в сравнении А вечность - как морской песок вечность превращается в характеризуемое, а характеризующим становится представление о песке. При этом важнейшая тут идея большого количества, безграничности, неисчислимости наперед связана и с первым, и с вторым.

Наконец, в метафоре Он осыпается с телеги - Не хватит на мешки рогож... характеризуемым по-прежнему остается вечность, а характеризующим песок, однако тут наши изначальные представления о вечности подвергаются существенному пересмотру. Вообще-то вечность скорее мыслится нами как (бесконечное) множество временных интервалов, чье событийное наполнение значительно, интересно, нередко также символично и таинственно, или, по крайней мере, временных интервалов, принципиально «открытых» подобному наполнению. Поэтому если у Осипа Мандельштама в начале четвертой строфы им приписаны, наоборот, избыточность, «сверхобилие», «малоценность», «оптовость», слабая индивидуализированность, то все эти смыслы вносятся в троп именно и только характеризующим компонентом, так что здесь характеризующее индуцирует в характеризуемом вообще-то чуждые ему свойства.

Таким образом, в стихотворении сначала появляется троп, где важные особенности характеризуемого лишь актуализированы характеризующим, а вдобавок именно характеризуемое, вопреки общему правилу, в немалой мере влияет на то, как мы мыслим характеризующее; затем троп, где важные особенности характеризуемого вновь лишь актуализируются характеризующим и при этом ощутимого влияния характеризуемого на характеризующее нет; наконец - троп, в котором характеризующее уже серьезно видоизменяет наши первоначальные представления о характеризуемом. Иначе говоря, все тропы очень строго упорядочены по возрастанию информативности.

Интуитивным фокусом этого стихотворения является вторая половина третьей строфы и первая половина четвертой или, возможно, четвертая строфа целиком. Так или иначе, все названные тропы выступают здесь в фокусе, поэтому при опреде- 
ленном взгляде на вещи маркером первого дискурсивного плана тут можно считать саму уже тропеичность.

С другой стороны, однако, очевидно, что содержание строк 13-14 становится продолжением начатой в строках 11-12 мысли и ее дальнейшим развитием, и в этом плане тринадцатая-четырнадцатая строки все-таки более важны, нежели две предшествующие, - и по крайней мере один из показателей этого их привилегированного ранга логично усмотреть как раз в том, что появляющемуся в них тропу присуща радикально более высокая информативность.

\section{0. ПРИМЕР 9}

Напоследок отметим, что повышенная информативность тропов может обеспечиваться не только описанным выше механизмом, не только особой серьезностью того сдвига, который тропом вносится в наши первоначальные представления о характеризуемом, но и иным путем, так сказать, «удвоенным» смыслом тропеических выражений.

Посмотрим на стихотворение Осипа Мандельштама:

1.

У тщательно обмытых ниш

В часы внимательных закатов

Я слушаю моих пенатов

Всегда восторженную тишь.

2.

Какой игрушечный удел,

Какие робкие законы

Приказывает торс точеный

И холод этих хрупких тел!

3 .

Иных богов не надо славить:

Они как равные с тобой,

И, осторожною рукой,

Позволено их переставить.

В эмпирической части стихотворения, в строфах 1-2, мы находим лишь метафоры, которые не могут быть верны буквально: не может быть в прямом смысле внимательным закат, восторженной тишь, игрушечным удел. Зато в фокусе стихотворения перед нами строки И, осторожною рукой, Позволено их переставить, которые допустимо понимать как метафору, но вместе 
с тем - допустимо $и$ буквально. В результате строками этими обретается такая «удвоенность» смысла, которая, видимо, и объясняет их несомненно первоплановый дискурсивный статус.

11. ПРИМЕР 10

Подобный же эффект возникает и в мандельштамовском стихотворении «Образ твой, мучительный и зыбкий...»:

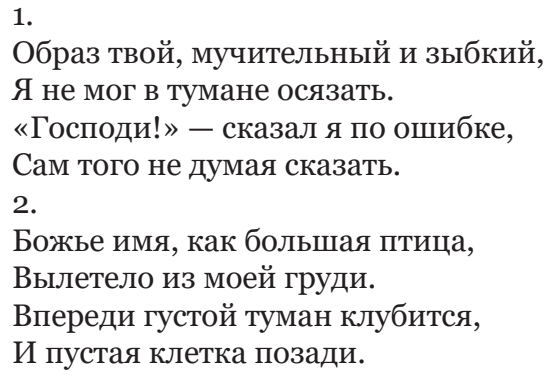

Легко видеть, что в начале стихотворения ни метафора 'мучительный образ', ни метафора 'осязать образ' в буквальном смысле верными быть не могут. Не может быть в прямом смысле верным и то, что ‘имя вылетело из груди’ в строках 5-6. Зато в конце появляются два предложения, Впереди густой туман клубится и И пустая клетка позади, которые допускают если не в равной, то в сопоставимой степени и метафорическую, и буквальную интерпретацию.

Интуитивно именно заключительные две строки тут являются главным претендентом на роль фокуса, и надо думать, что обязаны они этим, среди прочего, происходящей в них радикальной амплификации смысла.

\section{2. ЗАКЛЮЧЕНИЕ}

К сожалению, чтобы исследовать структуру тропов в достаточно представительной подборке стихотворений, требуется неимоверно трудоемкий анализ, предпринять который мы надеемся в будущем. Тем не менее, проанализированные нами сорок стихотворений свидетельствуют, что более высокая информатив- 
ность тропов типична в лирическом тексте именно для фокуса и должна считаться одной из его опознавательных примет: пик этой информативности, как она тут нами понимается, приходился на фокус в двадцати семи случаях из сорока, то есть примерно в два раза чаще, нежели на эмпирические фрагменты.

Если же принять во внимание то обстоятельство, что средняя длина эмпирической части, по нашим подсчетам, сделанным на материале около 2000 стихотворений, составляет 15,9 строки, а средняя длина фокуса 2,3 строки, то есть фокус приблизительно в семь раз (точнее, в 6,9 раза) короче, то реальная частотность интересующих нас пиков становится еще намного более высокой. Будь их распределение в лирическом тексте чисто случайным, на фокус они приходились бы почти всемеро реже, чем на эмпирические фрагменты, а значит, в свете наших подсчетов реальная вероятность их появления в фокусе даже не вдвое, а приблизительно в четырнадцать раз (!) выше, нежели вероятность их появления в нефокусных фрагментах текста.

Сверх этого, наш материал дает основания предполагать, что если в фокусе присутствует сразу несколько тропов, то наиболее важная его часть скорее будет связана с содержательно самъмм богатым из них - так что информативная структура тропов дополнительно способна служить внутренней иерархизации фокуca, его разделению на более тонкие дискурсивные подпланы.

Нет сомнения, что более тщательный и разносторонний анализ используемых лирикой тропов позволит обнаружить новые, глубокие и далеко не тривиальные связи между устройством последних и целостной структурой лирического текста.

\section{БИБЛИОГРАФИЯ}

Apresyan, Yuriy. "Glagoly momental'nogo deystviya i performativy v russkom yazyke.” Rusistika segodnya. Yazyk: sistema i yeye funktsionirovaniye. Moskva: Nauka, 1988 [Апресян, Юрий. “Глаголы моментального действия и перформативы в русском языке.” Русистика сегодня. Язык: система и ее функционирование. Москва: Наука, 1988].

Barsalou, Lawrence. "Context-independent and context-dependent information in concepts". Memory and Cognition 1982 no. 1.

Carston, Robin. Thoughts and Utterances. The Pragmatics of Explicit Communication. Oxford: Blackwell, 2002.

Fauconnier, Gilles, Turner, Mark. "Conceptual integration networks.” Cognitive Science 1988 no. 2. 
Gluksberg, Sam, Keysar, Boaz, "Understanding metaphorical comparisons: Beyond similarity." Psychological Review 1990 no. 97.

Ortony, Andrew. "Beyond literal similarity.” Psychological Review 1979 no. 86.

Paducheva, Yelena. "Rezul'tativnyye znacheniya nesovershennogo vida v russkom yazyke: obshchefakticheskoye i aktsional'noye znacheniye." Voprosy yazykoznaniya 1993 nо. 1 [Падучева, Елена. "Результативные значения несовершенного вида в русском языке: общефактическое и акциональное значение.” Вопросы языкознания 1993 по. 1].

Paducheva, Yelena. Semanticheskiye issledovaniya. Semantika vremeni $i$ vida $v$ russkom yazyke. Semantika narrativa. Moskva: Yazyki russkoy kul'tury, 1996 [Падучева, Елена. Семантические исследования. Семантика времени и вида в русском языке. Семантика нарратива. Москва: Языки русской культуры, 1996].

Sil'man, Tamara. Zametki o lirike. Leningrad: Sovetskiy pisatel', 1977 [Сильман, Тамара. Заметки о лирике. Ленинград: Советский писатель, 1977].

Sperber, Dan, Wilson, Deirdre. Relevance: Communication and Cognition. $2^{\text {nd }}$ edition. Oxford: Blackwell, 1995.

Talmy, Leonard. "Attention phenomena." The Oxford Handbook of Cognitive Linguistics. Ed. Dirk Geeraerts, Hubert Cuyckens. Oxford: Oxford University Press, 2010.

Wilson, Deirdre, Carston, Robin. "Metaphor, relevance, and the 'emergent property' issue." Mind and Language 2006 no. 3.

Zel'dovich, Gennadiy. Pragmatika grammatiki. Moskva: Yazyki slavyanskikh kul'tur, 2012 [Зельдович, Геннадий. Прагматика грамматики. Москва: Языки славянских культур, 2012].

Zel'dovich, Gennadiy. "O diskursivnoy perspective v liricheskoy poezii." Slova. Slova. Slova 2015 no. 2 [Зельдович, Геннадий. "О дискурсивной перспективе в лирической поэзии.” Слова. Слова. Слова 2015 no. 2].

Zel'dovich, Gennadiy. "Ob odnom sposobe markirovat' diskursivnuyu perspektivu v liricheskoy poezji. Kompozitsiya i referentsial'nyye svyazi, ili V chem nepravy P. Khopper i S. Tompson.” Linguistica Copernicana 2015 no. 12 [Зельдович, Геннадий. "Об одном способе маркировать дискурсивную перспективу в лирической поэзии. Композиция и референциальные связи, или В чем неправы П. Хоппер и С. Томпсон.” Linguistica Copernicana 2015 no. 12].

Zel'dovich, Gennadiy. “'Zolotoye secheniye' i kompozitsiya liricheskogo teksta.” Wiener Slawistischer Almanach 2016 Band 78 [Зельдович, Геннадий. “«Золотое сечение» и композиция лирического текста”. Wiener Slawistischer Almanach 2016 Band 78].

Zel'dovich, Gennadiy. Kompozitsiya liricheskogo stikhotvoreniya i "tesnota" stikhovogo ryada: Tipologicheskoye bogatstvo informatsii kak marker pervogo diskursivnogo plana v liricheskom tekste. Lyudmila Savchenko. Dusha vosplamenennaya. Khar'kov: Khar'kovskiy universitet, 2017. (In print) [Зельдович, Геннадий. “Композиция лирического стихотворения и «теснота» стихового ряда: Типологическое богатство информации как маркер первого дискурсивного плана в лирическом тексте.” Людмила Савченко. Душа воспламененная. Харьков: Харьковский университет, 2017. (In print)].

Zeldowicz, Gennadij. "Extraverted consciousness, introverted consciousness, and composition of lyrical discourse." Linguistica Copernicana 2016 no. 13. 
Gennadij Zeldowicz

\section{INFORMATYWNOŚĆ TROPÓW A KOMPOZYCJA TEKSTU LIRYCZNEGO}

Streszczenie

Artykuł poświęcony jest zasadniczemu podziałowi kompozycyjnemu tekstów lirycznych, polegającemu na tym, iż na planie dalszym tekstu przedstawia się pewne doświadczenie przeżywane przez autora (podmiot liryczny), na planie zaś bliższym - wynikające z tego doświadczenia odkrycie istotnej prawdy o charakterze bardziej ogólnym. Analizie poddana została rola, jaką w wyznaczaniu tego „rozłamu” odgrywa struktura tropów występujących w odpowiednim tekście. Przytoczone są argumenty na rzecz hipotezy, że istnieje mocna tendencja ku występowaniu tropów bogatszych informacyjnie na planie bliższym.

Gennadij Zeldowicz

\section{INFORMATIVENESS OF TROPES AND COMPOSITION OF LYRICAL TEXT}

Summary

The paper is concerned with the most basic compositional division to be found in lyrical texts, i.e. that between fragments referring to some kind of experience open to the author (lyrical subject), and fragments where the author, based on this experience, discovers an important more general truth. It is shown that this opposition may be marked by the structure of relevant tropes, since there is a strong tendency for more informative tropes to appear in fragments of the latter type. 